\title{
The impact of synchronous computer-mediated communication on EFL learners' motivation
}

Tahriri, Abdorreza $\measuredangle$

Department of English Language and Literature, University of Guilan, Iran (atahriri@gmail.com)

Hassaskhah, Jaleh

Department of English Language and Literature, University of Guilan, Iran (jaleh_hassaskhah@yahoo.com)

Mozafarian Pour, Azadeh

Department of English Language and Literature, University of Guilan, Iran (amozafarianpour@gmail.com)

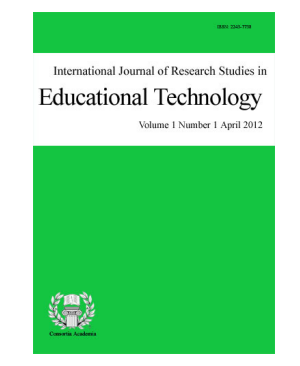

ISSN: $2243-7738$ Online ISSN: 2243-7746

OPEN ACCESS

\section{Abstract}

This study sought to investigate the impact of Synchronous Computer-Mediated Communication (SCMC) on EFL learners' motivation. To this end, 26 upper-intermediate female students from a language institute in Ahwaz, Iran participated in the present study. They were randomly assigned to two experimental groups and one control group. The two experimental groups received instruction in writing over two different Computer-Mediated Communication (CMC) mediums over the internet, Internet Relay Chat (IRC) $(n=8)$ and 2 Dimensional (2D) $(n=8)$ while the control group received instruction in a conventional face-to-face $(\mathrm{F} 2 \mathrm{~F})$ classroom environment $(\mathrm{n}=10)$. The data were collected through an Attitude/Motivation questionnaire prior to and after the experiment. The results of paired-samples t-tests showed that all three groups' level of motivation increased after the experiment; however, the results of one-way ANOVA and post-hoc tests revealed that only the differences between the experimental and control groups were statistically significant, $F$ $(2788.56,3400.97)=9.42, p=.001$. In addition, the difference between the two experimental groups (IRC and 2D) was not found to be significant. The findings of the present study might provide EFL instructors with practical guidelines on how on-line instruction could be planned to boost EFL learners' motivation.

Keywords: Synchronous Computer-Mediated Communication (SCMC); IRC; 2D; motivation; EFL 


\section{The impact of synchronous computer-mediated communication on EFL learners' motivation}

\section{Introduction}

Motivation has widely been accepted not only by teachers but also by researchers as a key factor that influences the rate and success of second language development. In fact, it provides an essential impetus for starting learning a second language (L2) and later the driving force to keep up with the often long and tiring process of learning (Dörnyei, 1998). "Indeed, all the other factors involved in L2 acquisition presuppose motivation to some extent" (Dörnyei, 1998, p. 117). Because of the central role attributed to motivation in language education, it has been the target of a large body of L2 research in the past decades (Moreira, 2004; Elspeth, 2005; Gökçe, 2008; Ebata, 2008; Kormos \& Kidle, 2009; Henry, 2012, Carrio-Pastor \& Mestre Mestre, 2014).

Ching (2012) rightly referred to the role of information technology in "the shift of the traditional literacies to the current notion of multiliteracies ... in an age of increased cultural diversity and global connectedness" (p. 3) which has brought about changes in learning and perceptions both. As a technological advancement, SCMC which has been the issue of concern to educators in recent years has also had a share in research on motivation; however, motivation has not been the central focus of SCMC studies but it has been examined as an additional factor (Sleesongsom \& Suppasetseree, 2009; Colon, 2011; Lin \& Kuo, 2011). On the other hand, most of the studies in the realm of SCMC have focused on students' perceptions rather than their motivation (Nowak, Watt, \& Walther, 2006; Yang, 2006; Xu, 2007; Ozdener \& Satar 2008; Algahtani, 2011; Khaled, 2012). Therefore, this study aimed at investigating the impact of SCMC on the EFL learners' motivation in particular.

Learners vary in the level and amount of their motivation upon their attendance of a given language course. For instance, some learners are highly motivated to learn a foreign language only because they love it and find learning other languages and the communication with different people fascinating (intrinsic motivation), while others are just attending the course for some external reasons such as the fear of failure in an English test or the aim of getting accepted at a job interview (extrinsic motivation). Yet, some others have a combination of both goals. On the other hand, some other internal or external factors might affect learners' motivation in a negative way. These factors might pertain to the stress and tension caused by the learning environment or by the teacher's instruction or behavior, or even by the institution's disciplines. For example, it is argued in some studies (McGuan, 2002; Rezai \& Zafari, 2010) that the confrontational nature of the oral discussions in traditional classrooms plays as an inhibiting factor for the learners' participation in class discussions and activities, which is especially true about shy learners. Subsequently, these, and other researchers propose SCMC as a possible solution to the problem of low motivation in EFL/ESL learners.

Unlike the past, the computer and internet are no longer accessories in people's lives; rather, they have become an inevitable part of every individual's life and career. Specifically, the internet technology, with its broad realm of facilities, has revolutionized the way people communicate with each other. This proliferating revolution has also had a great impact on education and specifically language learning.

A large body of research has so far investigated the effect of CMC on language learning and instruction. However, more research is required in this regard, specifically in SCMC, to provide a more comprehensive outlook of this expanding field. For example, according to Chou (2002) "as most distance learning environments utilize mainly asynchronous Computer-Mediated Communication (CMC) systems, interaction research that focuses on synchronous CMC is largely ignored" (p. 1). In addition, Jeong (2010) also stated that in spite of the wealth of research in SCMC, still there are some remaining gaps that need to be filled by further research. Moreover, Carswell (2002) believes that "most research into web-based asynchronous education has been 
The impact of synchronous computer-mediated communication on EFL learners' motivation

atheoretical, anecdotal, or descriptive in nature consisting of discussions of instructor and student experiences and 'how-to' guides. Quantitative information often consists of surveys of student satisfaction, using unvalidated instruments" (p. 476).

In light of what has been mentioned, and with regard to the importance of the construct of motivation which has somehow been ignored in the existing body of research on SCMC, this exploratory study intends to examine the effect of Synchronous Computer-Mediated Communication (SCMC) on the EFL learners' motivation in comparison to the traditional face-to-face (F2F) classroom environment.

\section{Literature Review}

In this part, existing literature is reviewed into two sections: 1) the research body on motivation and L2 learning, and 2) the body of research on SCMC and L2 learning.

\subsection{Motivation and L2 Learning}

In the field of L2 education, there has been a wealth of studies in both EFL and ESL contexts (Root, 1999; Igoudin, 2008; Norris-Holt, 2011; Stoffa, Kush, \& Heo, 2010; Xiao, 2011; Tsai \& Chang, 2013, to mention a few). These studies revealed that motivation not only has a positive role in language learning but it is also an essential component in learning a second or foreign language. For example, Xiao (2011) stated that motivation influences various aspects of language learning, such as the use of language learning strategies, learners' achievement in assessments related to their courses, the level of proficiency that they finally achieve, and the likelihood that they will continue to develop competency in the target language after completing the formal studying of the language in the classroom.

\subsection{SCMC and L2 Learning}

There has been a large body of research on the effect of SCMC on second/foreign language learning (Liu \& Sadler, 2003; Chiu \& Savignon, 2006; Sarieva, 2009; Jeong, 2010; Tayebinik \& Puteh, 2012; Samani \& Noordin, 2013; Saleh Mahdi, 2014; and many others).

Numerous studies have reported a positive effect for SCMC on the learning experience of the students. For instance, Rezai and Zafari (2010) mentioned a number of positive characteristics for SCMC that apparently help to enhance learners' oral proficiency skills as the following: 1) the text-based nature of interaction in SCMC provides the learners with the possibility of seeing the language of communication at the same time of the conversation. In addition, the time lag between giving and receiving the message provides them with enough time to reflect on and analyze the content of the message in order to produce a proper answer; 2) SCMC reduces student's anxiety that is caused by the time pressure of oral conversations. Moreover, it can solve the students' psychological barrier of shyness or fear of embarrassment or receiving negative feedback from others; and 3) SCMC reduces the role of the teacher from full authority, as it is in the traditional classroom, to a less dominant position, which enhances learner autonomy in terms of giving and receiving feedback and output and consequently puts them in the position to gain control of the learning process.

In a study by Sullivan and Pratt (1996), they compared students in two ESL writing environments: a networked computer-assisted and a traditional oral classroom. The focus of the study was on the quantitative differences in attitude and writing performance and the qualitative analysis of participatory patterns and discourse in the two classrooms. The study was conducted on 38 intermediate ESL students, whose first language was Spanish, at the University of Puerto Rico. All of the students had previous exposure to the computer in their other courses but they had little or no experience in writing formal compositions. The experiment was conducted over a fifteen-week period during which both classes had to complete four compositions. The results indicated that the computer-assisted class had greater overall improvement for each of the three measurements over the oral classroom. However, the results of the Writing Apprehension Scale (WAS) 
showed no significant differences in the writing apprehension of the participants between the two classes; the two classes had similar apprehension levels. The students' attitudes towards writing were positive in both classes, but the students in the computer-assisted classroom began with significantly more positive attitudes and their positive attitudes continued to stay higher until the end of the fifteen weeks. The students' writing scores indicated a significant change in the writing skills of the two classes during the term. The scores of the oral class decreased significantly while the scores of the computer-assisted class increased significantly, indicating that the computer-assisted class had a more positive effect on the students' writing ability.

Salaberry (2000) compared the effect of pedagogical tasks implemented in synchronous face-to-face tasks to text-based computer mediated communication. The target grammatical feature was the past tense verbal endings in Spanish as a second language. Data were gathered from three tasks completed by four English-speaking students studying Spanish as a second language at a research university in the US. One of them had a lower 3rd grade and the other three had a higher 3rd grade overall Spanish course level at the time of the experiment. For the purpose of the study, three broad stages of the developmental sequence proposed by Andersen were considered: present tense (no past tense marking), preterite (achievements and accomplishments), and imperfect (states). Participants were asked to complete three tasks in the form of real-time conversations that were conveyed through a software program called "Aspects". Each CMC session, as was the case for the oral interview, lasted almost one hour. At the end of each session, the transcripts of the conversation exchanges were gathered for analysis. Salaberry reported that the first changes in morphosyntactic developmental stages were observed more clearly in the computer-based interaction task than in the face-to-face oral task. He further concluded that "it is, thus, possible that aspectual distinctions marked through morphosyntactic means are made more salient in a written interactional format that maintains the functional focus of typical on-line face-to-face exchanges" (p. 23). He also claimed that the results of his study provide further support for previous arguments about "the likelihood that power relationships are differently instantiated in electronic and face-to-face environments, that interlocutor scaffolding may be equally beneficial in both interactional settings, and that CMC sessions introduce novel methodological factors for the analysis of L2 discourse data" (p. 23). However, Salaberry mentioned that it was only a pilot study with a small number of participants for which no measures of validity or reliability were claimed.

Theoretical support for the use of CMC in language education comes from Long's (1996) Interaction Hypothesis. Long presented the Interaction Hypothesis for the first time in his 1996 paper entitled 'The role of the linguistic environment in second language acquisition.' In this hypothesis, Long emphasized the role of learner interaction in the learning of a second language. Like Krashen's Input Hypothesis, he also believes that comprehensible input is a very important factor for second language acquisition (Ellis, 1997). Within the Input Hypothesis, Long integrates two theories of language learning: the 'Input' and the 'Output' hypotheses. In the Input Hypothesis, he proposed that in order for the learner to learn the structure and vocabulary of the target language, he should be exposed to input through listening and reading materials. On the other hand, the Output Hypothesis claims that speaking and writing are necessary activities for the learner to help him retain and remember the language. By integrating 'input' and 'output', the Interaction Hypothesis claims that interaction is not only a way for the learner to study a language, but it also gives him a chance to practice what he has learned (see https://twitter.com/wiseGEEK). Long placed the main focus on the importance of the establishment of quality for building meaning throughout negotiation, rather than relying only on quantity for interactional conversations (Alkhateeb, 2014).

\subsection{Research Question and Hypothesis}

In order to address the gap in SCMC research that was mentioned above, the present study was an attempt to investigate whether or not SCMC enhances EFL learner's motivation. More specifically, the following research question and hypothesis were formulated for this study:

RQ: Does SCMC enhance EFL learners' motivation for learning English more than the face-to-face 
classroom environment?

H0: SCMC does not have any significant effect on EFL learners' motivation for learning English.

\section{Methodology}

This study followed a quantitative method of data collection and analysis. Two different modes of SCMC environments (Internet Relay Chat and 2 Dimensional) formed the experimental groups and a conventional face-to-face (F2F) class was the control group in the present study.

\subsection{Participants}

A total of 26 upper-intermediate female students of a private language institute in Ahwaz, Khuzestan province, Iran were randomly selected as the participants of the present study. The institute was chosen based on convenience sampling. The participants were then randomly assigned to two experimental (IRC: 8; 2D: 8) and one control groups (F2F: 10). The average age of the participants was $(\mathrm{M}=20.73)$. The students' first language was Persian. All of them had already taken at least three years of English instruction in the same institute, with an average grade of 75 , which was the pass score in that institute.

\subsection{Instruments}

The instruments utilized in the study were a background questionnaire, a placement test, an Attitude/Motivation questionnaire and two types of SCMC programs, Internet Relay Chat (IRC) and 2 Dimensional (2D).

Placement test - To control the possible effect of proficiency level, a placement test was given to the participants (Appendix A). The students were provided with a set of data based on which they had to answer a question in the form of a 4-5 paragraph essay during a time limit of 70 minutes. Then the essays were scored on the basis of a number of components including essay organization, clarity of argument, paragraph and sentence structure, and grammar and mechanics. The exam markers used ELPE Rubric to evaluate the essays. Additionally, there were multiple checks to ensure ongoing consistency. The reliability of this test was measured by Cronbach's Alpha, the results of which showed an alpha coefficient of .83, indicating that the test had a good index of reliability (Clark \& Watson, 1995).

Background questionnaire - In addition, all the participants were given a questionnaire that asked them about their familiarity with computers, which was adopted from the study of Yilmaz (2007) and was adapted to the context of the present study (Appendix B). The reliability of the questionnaire was measured by Cronbach's Alpha, and the results showed an alpha coefficient of .78.

Attitude/Motivation Questionnaire - The participants' motivation was examined both before and after the experiment through an Attitude/Motivation questionnaire, which was developed by three researchers in the EFL context, namely, Tatsuya Taguchi from Japan, Michael Magid from China and Mostafa Papi from Iran. It is a 6-point Likert-scale questionnaire including 67 questions on the English learners' motivation. The questionnaire was first piloted on a group of upper-intermediate students with similar characteristics to the target population at the same institute before being used for the target sample. The reliability of the questionnaire was calculated through Cronbach's Alpha, and the result was .84 which is considered to be good in terms of its reliability (Clark \& Watson, 1995).

SCMC programs - The two SCMC programs that were used in the present study were IRC and 2D. Internet Relay Chat (IRC) is an earlier type of SCMC services and provides the users with the ability to chat with one another in pairs or groups via written texts on screens that are visible to all the participants. One common IRC software is Yahoo messenger, which was chosen in this study for its convenience and commonality among almost all computer and internet users. An additional reason for choosing IRC was that it does not require a high 
Tahriri, A., Hassaskhah, J., \& Mozafarian Pour, A.

internet bandwidth or speed.

2 Dimensional (2D) is a more recent and developed type of SCMC, which is a rudimentary form of virtual reality. This environment enables the users to use more sophisticated facilities than text only to communicate with each other. The background can include a wide variety of places, such as a conference room, a classroom, a tavern or any other kind of virtual places where the students can hold a discussion or conversation with a real-like atmosphere and feeling. Furthermore, this virtual world usually has more than one room and the students can navigate from room to room, and "if it has been structured well, the navigation becomes part of the educational experience along with the visual backgrounds and the conversations" (Ingram, Hathorn, \& Evans, 2000, p. 22).

The 2D program that was chosen for this study was Palace Chat (http://www.palacechat.org). It consists of a palace with several rooms, a hall, an office, a laboratory, a club, and many other places. In order to have more privacy, it is also possible to add your own room, assign a name to it, and even lock it. This program does not require a high internet bandwidth.

\subsection{Procedure}

Administration of the background questionnaire, placement test, and attitude/motivation questionnaire After obtaining consent from the students to participate in the course, the background questionnaire was distributed among them to be completed. After that, all the participants sat the ELPE placement test. To obtain the fairest results, all the three groups took the placement test at the same time and in the same room. Based on the guidelines of the administration of this test, it started with a brief explanation about the procedure of taking it and then pages of the questions were given to the participants. They were placed in an imaginary situation of being a trainee to become a salesperson in Ford Company, and were provided with a table of information about three models of Ford and were asked to answer a question that required them to explain which vehicle would be the best choice for a young family. The essay had to start with an introduction and thesis statement, and then in the body they were required to explain why members of a young family would benefit from the car that they were promoting. In the end, the essay had to finish with a conclusion. When the essays were evaluated based on the ELPE Rubrics, it turned out that all the scores fell between 60-65; therefore, all the participants were considered to be at the same level of proficiency. Before the experiment, all the participants were given the Attitude/Motivation questionnaire with the purpose of examining their motivation towards learning English and the use of it prior to taking the course in order to see whether any of the mediums of instruction would have any effect on increasing it and to what extent. The questionnaire had already been piloted on a group of 20 students at the same level of proficiency similar to the target participants to make sure it was appropriate and reliable. Finally, after the experiment, the Attitude/Motivation questionnaires were distributed among the students of the three groups in order to make a comparison between the level of the students' motivation before and after taking the course.

Practice sessions - To eliminate the possible role of low internet skills, the participants of the two experimental groups spent four one-hour practice sessions before the beginning of the course. In the first session, they were made familiar with computer and typing. In the second session, Dropbox and its application was introduced to them. In the third session, installation and use of Yahoo Messenger (for IRC group) and Palace Chat (for 2D group) and their facilities were introduced and practiced. Finally, in the fourth session, the whole materials taught in the three previous sessions were reviewed.

Treatment - After the practice sessions, the three groups were handed the course schedule and requirements. According to the program, all the three groups were required to meet two sessions per week. The three groups attended classes for 10 sessions ( 5 weeks), during which the students of the three groups were instructed on general academic writing, including the basic structures of academic texts, paragraph writing, sequence markers, connectives, etc. They were also taught the use of some structures that were necessary for writing their post-test 
letter, such as the types and uses of different patterns of development including classification, exemplification and comparison and contrast. The tenth session was a review session of all the materials discussed and taught, problem shooting, further feedback from the students and the instructor, and finally, a complete explanation about the post-test essay that the students had to write and submit in line with the learned materials.

Before the beginning of the classes, the two experimental groups were invited to a folder entitled 'Academic Writing Course' that was inside the teacher's Dropbox. It was the main shared folder between all the students of the virtual classes and the teacher. The instructor placed a PowerPoint of the main topic and the materials that were going to be taught each session in addition to the authentic essays in Dropbox a day before each session in order to give the students a chance to be prepared for the lesson that was going to be worked on in the class. It was deemed necessary since the classes were merely text-based, and it would be difficult for them to start each session having no idea of the lessons. At the end of each session, the teacher put the homework assignments to be completed by the students in the Dropbox for them to pick with a deadline for their submission, and the students, in return, put their completed assignments back there for the teacher to collect.

The IRC group and the 2D group attended their classes in "Yahoo Messenger" and "Palace Chat" respectively while the control group met at the institute and attended a conventional F2F class. All the programs and materials were the same in the three groups, except for the medium of instruction.

\subsection{Data Analysis}

In order to obtain a comprehensive account of the students' motivation, both within-group and between-group changes were examined. For within-group motivation, the change of motivation in the same group was investigated to see if any difference existed. To this end, the data from each group were analyzed through paired samples t-test. For between-group motivation, changes and degree of motivation among the three groups were examined to see which medium of instruction had more effect on the students' motivation and whether that amount was high enough to have statistical significance. As such, the results were compared statistically via one-way ANOVA. The degree of significance for the present study was measured at $p<.05$.

\section{Results}

\subsection{Tests of Normality of Distribution}

The data were first analyzed in terms of the normality of distribution (see Table 1):

\section{Table 1}

One-sample Kolmogorov-Smirnov test

\begin{tabular}{llccccc}
\hline \multirow{2}{*}{$\mathrm{N}$} & & Score 1 & Mean 1 & Score 2 & Mean 2 & Y \\
\cline { 2 - 7 } Normal Parameters $^{\mathrm{a}, \mathrm{b}}$ & & 26 & 26 & 26 & 26 & 26 \\
\hline & Mean & 230.5000 & 3.4403 & 293.8077 & 4.3852 & 63.3077 \\
& Std. Deviation & 18.34176 & .27376 & 28.35492 & .42321 & 15.73472 \\
\hline \multirow{2}{*}{ Most Extreme Differences } & Absolute & .137 & .137 & .131 & .131 & .175 \\
& Positive & .137 & .137 & .131 & .131 & .129 \\
Kolmogorov-Smirnov Z & Negative & -.110 & -.110 & -.119 & -.119 & -.175 \\
\hline Asymp. Sig. (2-tailed) & & .698 & .698 & .666 & .666 & .891 \\
\hline
\end{tabular}

Note. a. Test distribution is Normal. b. Calculated from data.

As table 1 shows, based on one-sample Kolmogorov-Smirnov Z-test statistics, the p-values were not statistically significant $(p>.05)$. As such, the sample could be argued to be normally distributed. 
Tahriri, A., Hassaskhah, J., \& Mozafarian Pour, A.

The results, Table 2, revealed no statistically significant differences between the experimental groups and the control group before the treatment, $F(984.52,7425.97)=1.52, p=.23$.

\section{Table 2}

One-way ANOVA (Motivation pre-test scores)

\begin{tabular}{lccccc}
\hline & Sum of Squares & df & Mean Squared & F & Sig. \\
\hline Between Groups & 984.525 & 2 & 492.262 & 1.525 & .239 \\
Within Groups & 7425.975 & 23 & 322.868 & & \\
Total & 8410.500 & 25 & & & \\
\hline
\end{tabular}

Table 3 provides the descriptive statistics of the three participant groups in terms of motivation:

As table 3 shows, the mean of 2D group ( $M=73)$ was the highest of all followed by those of IRC group $(M=69.87)$ and control group $(M=50.3)$ respectively. One-way ANOVA was run to see whether there was a significant difference among the three groups in terms of motivation.

Table 3

Descriptive statistics of the three groups' motivation (Post-tests)

\begin{tabular}{|c|c|c|c|c|c|c|c|c|}
\hline & \multirow[t]{2}{*}{$\mathrm{N}$} & \multirow[t]{2}{*}{ Mean } & \multirow[t]{2}{*}{ Std. Deviation } & \multirow[t]{2}{*}{ Std. Error } & \multicolumn{2}{|c|}{$\begin{array}{l}\text { 95\% Confidence Interval for } \\
\text { Mean }\end{array}$} & \multirow[t]{2}{*}{ Min. } & \multirow[t]{2}{*}{ Max. } \\
\hline & & & & & Lower Bound & Upper Bound & & \\
\hline IRC & 8 & 69.8750 & 14.09597 & 4.98368 & 58.0905 & 81.6595 & 44.00 & 93.00 \\
\hline $2 \mathrm{D}$ & 8 & 73.0000 & 13.28802 & 4.69802 & 61.8909 & 84.1091 & 49.00 & 87.00 \\
\hline Control & 10 & 50.3000 & 9.27422 & 2.93277 & 43.6656 & 56.9344 & 34.00 & 63.00 \\
\hline Total & 26 & 63.3077 & 15.73472 & 3.08583 & 56.9523 & 69.6631 & 34.00 & 93.00 \\
\hline
\end{tabular}

Table 4 gives the results of one-way ANOVA run on the post-intervention data:

\section{Table 4}

One-way ANOVA (Motivation post-test scores)

\begin{tabular}{lccccc}
\hline & Sum of Squares & $d f$ & Mean Squared & F & Sig. \\
\hline Between Groups & 2788.563 & 2 & 1394.282 & 9.429 & .001 \\
Within Groups & 3400.975 & 23 & 147.868 & & \\
Total & 6189.538 & 25 & & & \\
\hline
\end{tabular}

The results showed a significant difference between the experimental groups and the control group after the treatment, $F(2788.56,3400.97)=9.42, p=.001$. For further comparison of the results, the Tukey Post Hoc test was run. The results showed statistically significant differences among the three groups in terms of motivation after the experiment. However, the difference between the two experimental groups (IRC and 2D) was not statistically significant. Table 5 reports the results of the Post Hoc tests.

It can be concluded that between the two modes of instruction (SCMC and F2F), SCMC mode of instruction proved more successful in boosting the participants' motivation for learning than the traditional F2F context; this statistically significant difference was not found between the IRC and 2D groups, though students reported a partially higher degree of motivation in the 2D group. Therefore, the results imply that the mode of instruction may have a significant effect on the students' motivation in learning a foreign language. 
The impact of synchronous computer-mediated communication on EFL learners' motivation

Table 5

Multiple comparisons of motivation results (Post-hoc tests)

\begin{tabular}{|c|c|c|c|c|c|c|c|}
\hline & \multirow[t]{2}{*}{ (I) group } & \multirow[t]{2}{*}{ (J) group } & \multirow{2}{*}{$\begin{array}{c}\text { Mean } \\
\text { Difference } \\
(\mathrm{I}-\mathrm{J})\end{array}$} & \multirow[t]{2}{*}{ Std. Error } & \multirow[t]{2}{*}{ Sig. } & \multicolumn{2}{|c|}{$95 \%$ Confidence Interval } \\
\hline & & & & & & Lower Bound & Upper Bound \\
\hline \multirow{6}{*}{ Tukey HSD } & \multirow{2}{*}{ IRC } & $2 \mathrm{D}$ & -3.12500 & 6.08006 & .865 & -18.3515 & 12.1015 \\
\hline & & Control & $19.57500^{*}$ & 5.76805 & .007 & 5.1299 & $34.0201^{*}$ \\
\hline & \multirow{2}{*}{$2 \mathrm{D}$} & IRC & 3.12500 & 6.08006 & .865 & -12.1015 & 18.3515 \\
\hline & & Control & $22.70000^{*}$ & 5.76805 & .002 & 8.2549 & $37.1451^{*}$ \\
\hline & \multirow{2}{*}{ Control } & IRC & $-19.57500^{*}$ & 5.76805 & .007 & -34.0201 & $-5.1299^{*}$ \\
\hline & & $2 \mathrm{D}$ & $-22.70000^{*}$ & 5.76805 & .002 & -37.1451 & $-8.2549^{*}$ \\
\hline \multirow{6}{*}{ LSD } & \multirow{2}{*}{ IRC } & $2 \mathrm{D}$ & -3.12500 & 6.08006 & .612 & -15.7026 & 9.4526 \\
\hline & & Control & $19.57500^{*}$ & 5.76805 & .002 & 7.6429 & $31.5071^{*}$ \\
\hline & \multirow{2}{*}{$2 \mathrm{D}$} & IRC & 3.12500 & 6.08006 & .612 & -9.4526 & 15.7026 \\
\hline & & Control & $22.70000^{*}$ & 5.76805 & .001 & 10.7679 & $34.6321^{*}$ \\
\hline & \multirow{2}{*}{ Control } & IRC & $-19.57500^{*}$ & 5.76805 & .002 & -31.5071 & $-7.6429^{*}$ \\
\hline & & $2 \mathrm{D}$ & $-22.70000^{*}$ & 5.76805 & .001 & -34.6321 & $-10.7679^{*}$ \\
\hline
\end{tabular}

Note. $*$ The mean difference is significant at the .05 level.

\subsection{Within-Group Analyses}

In order to investigate the differences in the degree of motivation within each group before and after the experiment, paired-samples t-tests were used. The results of each test are reported separately in the following sections. Results from the paired-samples statistics for the IRC group showed a difference in the scores of the students before $(M=223.12, S D=17.87)$ and after $(M=293, S D=24.81)$ the experiment. Table 6 summarizes the results of the paired-samples statistics for the IRC group before and after the experiment.

Table 6

Paired-samples statistics (IRC group)

\begin{tabular}{ccccc}
\hline & Mean & N & Std. Deviation & Std. Error Mean \\
\hline Post-test & 293.0000 & 8 & 24.81359 & 8.77293 \\
Pre-test & 223.1250 & 8 & 17.87606 & 6.32014 \\
\hline
\end{tabular}

Table 7 shows the results of the paired-samples statistics for the 2D group:

Table 7

Paired-samples statistics (2D group)

\begin{tabular}{ccccc}
\hline & Mean & N & Std. Deviation & Std. Error Mean \\
\hline Post-test & 311.7500 & 8 & 28.28806 & 10.00134 \\
Pre-test & 238.7500 & 8 & 17.78242 & 6.28703 \\
\hline
\end{tabular}

The paired-samples statistics for the 2D group also showed an increase in the pre-test scores $(M=238.75$, $S D=17.78)$ after the treatment $(M=311.75, S D=28.28)$. The results of the paired-samples t-test for the F2F (control) group also showed an increase between the scores of the students prior to $(M=229.80, S D=18.18$ ) and after $(M=280.10, S D=25.22)$ the experiment. Table 8 reports the results of the paired-samples statistics for the F2F group: 
Tahriri, A., Hassaskhah, J., \& Mozafarian Pour, A.

\section{Table 8}

Paired-samples t-test (F2F group)

\begin{tabular}{ccccc}
\hline & Mean & N & Std. Deviation & Std. Error Mean \\
\hline Post-test & 280.1000 & 10 & 25.22983 & 7.97837 \\
Pre-test & 229.8000 & 10 & 18.18302 & 5.74998 \\
\hline
\end{tabular}

Paired-samples t-tests were run to check the statistical significance of the differences. Table 9 shows the results of paired-samples t-test for the three groups.

Table 9

Paired-samples $t$-tests for the three groups

\begin{tabular}{lccc}
\hline & $T$ & $d f$ & Sig. (2-tailed) \\
\hline IRC Group & 14.02 & 7 & .000 \\
2D Group & 15.53 & 7 & .000 \\
F2F Group & 17.15 & 9 & .000 \\
\hline
\end{tabular}

As table 9 shows, the results from the paired-samples t-test for the IRC group showed a statistically significant difference in the scores of the students after the experiment, $t(7)=14.02, p=.000$. For the $2 \mathrm{D}$ group, a statistical significance in the difference of the scores after the experiment was found, $t(7)=15.53, p=.000$. The results of the paired-samples t-test for the F2F (control) group also showed a significant difference between the scores of the students prior to and after the experiment, $t(9)=17.15, p=.000$.

To sum up, the paired-samples t-tests revealed that there were significant differences between the scores before and after the experiment in all the three groups ( 2 experimental and 1 control), but the two experimental groups showed a larger amount of difference than the control group. In addition, the 2D group showed higher improvement than the IRC group and control group in terms of motivation respectively.

\section{Discussion}

The present study intended to investigate the effect of SCMC on the students' motivation for learning English. To this end, an attitude/motivation questionnaire was administered before and after the experiment to see whether there would be a difference in the degree of motivation in any of the three participant groups (IRC, 2D and F2F). The findings of the study suggested a significantly higher degree of motivation in the two experimental groups (2D and IRC respectively) in comparison to the F2F group; however, the difference between the two SCMC groups was not statistically significant.

The findings of the present study are in line with those of Albaali (2010) who investigated the effect of the Interactive Whiteboard (IWB) on the ESL students' essay writing and their attitudes towards writing. It was an experimental study conducted on 60 Egyptian medical students who were randomly assigned to two groups: an experimental group that was instructed through IWB and a control group that was instructed in the traditional pen and pencil plus whiteboard method. The results showed no significant effect for IWB on the students' attainment of essay writing (a non-significant effect size of -0.18), while they showed a positive effect for the IWB on the students' attitudes towards both writing and the board itself (effect size of 1.88).

Furthermore, the results of the study of Algahtani (2011) on the effectiveness of the e-learning experience on the students' perceptions which was conducted on male university students in Saudi Arabia, are in line with the findings of the present study. The data were gathered from interviews with 31 students from two universities and then the oral data were transcribed. The findings suggested that the students reported of being motivated by the interactivity of e-learning to pursue their course intensively and successfully. Moreover, the participants "appreciated the opportunities offered by e-learning and the way it supported their studies, facilitating 
The impact of synchronous computer-mediated communication on EFL learners' motivation

communication and accommodating their learning needs and circumstances. They recognized that it helped to meet an increased demand for learning" (p. i). The findings of the study are also in line with the studies of Ozdener and Satar (2008), Sleesongsom and Suppasetseree (2009) and Khaled (2012), all of which suggested enhanced learner motivation through learning in the SCMC context.

\section{Conclusions}

Motivation is considered central to learning a second/foreign language by both researchers and teachers. It is important to the degree that Dörnyei (1998) believes that "without sufficient motivation, even individuals with the most remarkable abilities cannot accomplish long-term goals, and neither are appropriate curricula and good teaching enough on their own to ensure student achievement. On the other hand, high motivation can make up for considerable deficiencies both in one's language aptitude and learning conditions" (p. 117).

This study sought to examine the effect of SCMC on the motivation of EFL learners. The main incentive for conducting the study was that despite the essential role of motivation in language learning, it did not have a good share in the current SCMC research. The findings of the present study revealed that teaching through the medium of SCMC has a more beneficial effect on the enhancement of the motivation of the students compared to the traditional face-to-face context. The SCMC classes provided the participants with a large variety of channels to communicate with each other (private chats, e-mail, texting, etc.) and helped them search and share information at the same time of discussing issues in the class.

On the teaching level, the findings indicated that through utilizing new technology, teachers can be more creative in their teaching and also the techniques that they use to teach every aspect of the language can be tailored to be more engaging and at the same time more appealing for the students. In fact, they can monitor the process of learning every moment through keeping in touch with the students over the internet.

The findings resulting from this study made some contributions to the educational and institutional aspects of online education. They confirmed the capability of an online learning system to enhance the EFL students' motivation at an academic level. It was also proved that new technology, and specifically SCMC, with its wide variety of facilities is a good source for both teachers and institutions to benefit from in making the otherwise tedious process of language learning a smooth, varied and at the same time enjoyable experience.

From the learning perspective, the findings of the present study also showed that students preferred the SCMC mode of instruction because of providing them with further facilities for learning as well as being less time- and place-constrained and less confrontational, and most importantly for being less stressful. SCMC provided them with the possibility of being in touch with their classmates and also with the teacher all the time, indicating that they were in touch with the whole learning process and the language that they were trying to learn continuously. Moreover, the fact that they preferred English as their language of communication over the internet was another proof that online communication was more encouraging for them to engage in the target language use.

\section{Suggestions for Further Research}

Still, more research is needed to investigate both similarities and differences between the two modes (SCMC and F2F) and different varieties of the SCMC mode, such as IRC and 2D, to benefit from the implementation of SCMC technology in language instruction and classrooms. For instance, since participants in the present study consisted of female EFL learners only, research might be needed on male students, or a combination of both genders, in order to gain a more comprehensive outlook of this issue. Another suggestion for further research is the effect of on-line instruction on other learning issues, such as learner differences, culture and community, or behavioral limitations. Finally, further research might be suggested for the investigation of the impact of SCMC on more specific aspects of motivation, such as intrinsic, extrinsic, instrumental, etc. 


\section{References}

Albaali, E. A. M. S. (2010). The impact of the interactive whiteboard on medical school students' ESL essay writing (Doctoral Dissertation). Durham University. Retrieved from http://etheses.dur.ac.uk/563/

Algahtani, A. F. (2011). Evaluating the effectiveness of the E-learning experience in some universities in Saudi Arabia from male students' perceptions. Doctoral Dissertation, Durham University. Retrieved from http://etheses.dur.ac.uk/3215/

Alkhateeb, A. A. (2014). Hypothesis of interaction: Reflections on its theoretical and practical contributions for second language acquisition (SLA). Studies in English Language Teaching, 2(3), 294-305.

Carrio-Pastor, M. L., \& Mestre Mestre, E. M. (2014). Motivation in second language acquisition. Procedia Social and Behavioral Sciences, 116, 240-244. http://dx.doi.org/10.1016/j.sbspro.2014.01.201

Carswell, A. D. (2002). Learner outcomes on an asynchronous distance education environment. International Journal of Human-Computer Studies, 56, 475-494. http://dx.doi.org/10.1006/ijhc.2002.1004

Ching, G. S. (2012). Blog assisted learning: Experiences in learning Business English vocabularies. International Journal of Research Studies in Educational Technology, 1(1), 3-12. http://dx.doi.org/10.5861/ijrset.2012.v1i1.10

Chou, C. C. (2002). A comparative content analysis of student interaction in Synchronous and Asynchronous learning networks. Paper presented at The 35th Hawaii International Conference on System Sciences. IEEE Computer Society, Hawaii. Retrieved from http://www.computer.org/csdl/proceedings/hicss/2002/1435/05/14350134b.pdf http://dx.doi.org/10.1109/HICSS.2002.994093

Clark, L. A., \& Watson, D. (1995). Constructing validity: Basic issues in objective scale development. Psychological Assessment, 7(3), 309-319. http://dx.doi.org/10.1037/1040-3590.7.3.309

Colon, V. A. (2011). Using web 2.0 tools in a foreign language classroom: motivating students through virtual social interaction to improve reading and writing skills. Doctoral Dissertation, University of Georgia. Retrieved from http://purl.galileo.usg.edu/uga\%5Fetd/colon\%5Fvictor\%5Fa\%5F201105\%5Fphd

Dörnyei, Z. (1998). Motivation in second and foreign language learning. Language Teaching, 31(3), 117-135. http://dx.doi.org/10.1017/S026144480001315X

Ebata, M. (2008). Motivation factors in language learning. The International TESL Journal, XIV(4). Retrieved from http://iteslj.org/Articles/Ebata-MotivationFactors.html

Ellis, R. (1997). Second language acquisition. Oxford: Oxford University Press.

Elspeth, B. (2005). Language learning motivation: Who do you want to be? Language Learning Journal, 31(1), 69-74. http://dx.doi.org/10.1080/09571730585200101

Gökçe, S. (2008). Attitudes and motivational intensity of foreign language learners at vocational high schools: A comparative study. Master's Thesis, Middle East Technical University. Retrieved from http://etd.lib.metu.edu.tr/upload/3/12609935/index.pdf

Henry, A. (2012). L3 motivation (Master's Thesis). Gothenburg University. Retrieved from http://hdl.handle.net/2077/28132

Igoudin, A. L. (2008). Adult ESL student motivation for participation in advanced language learning. The CATESOL Journal, 20(1), 27-48.

Ingram, A. L., Hathorn, L. G., \& Evans, A. (2000). Beyond chat on the internet. Computers \& Education, 35, 21-35. http://dx.doi.org/10.1016/S0360-1315(00)00015-4

Jeong, E. (2010). Comparison between the effects of SCMC and SCMC with peer feedback on EFL writing. Multimedia-Assisted Language Learning, 13(2), 81-103.

Khaled, A. (2012). The effectiveness of a CALL multimedia classroom on L2 learners achievements, attitudes and the word solving strategies' frequencies and the perceptions of helpfulness, when compared with learners in traditional classrooms: A quasi-experimental study. Doctoral Dissertation, Durham University. Retrieved from http://etheses.dur.ac.uk

Kormos, J., \& Kiddle, T. (2009). The role of socio-economic factors in motivation to learn English as a foreign language: The case of Chile. Retrieved from 
The impact of synchronous computer-mediated communication on EFL learners' motivation

http://eprints.lancs.ac.uk/63008/1/chilesocioeconomicfactors.pdf

Lin, J., \& Kuo, Ch. (2011). Online peer conferencing in academic writing. The Jalt Call Journal, 7(2), 121-136.

Liu, J., \& Sadler, R.W. (2003). The effect and affect of peer review in electronic versus traditional modes on L2 writing. Journal of English for Academic Purposes, 2, 193-227.

http://dx.doi.org/10.1016/S1475-1585(03)00025-0

Long, M. (1996). The role of the linguistic environment in second language acquisition. In W. C. Ritchie, \& T.

K. Bhatia, (Eds.), Handbook of second language acquisition (pp. 413-468). San Diego: Academic Press.

McGuan, S. (2002). Asynchronous computer-mediated conferencing to support learning and teaching: An action research approach. Journal of Hospitality, Leisure, Sport and Tourism Education, 1(1). Retrieved from www.hlst.ltsn.ac.uk/johlste

Moreira, M. L. G. D. L. (2004). Investigating the inter-relationships between beliefs, autonomy, and motivation in the context of foreign language learning/teaching. Rev. Brasileira de Lingüística Aplicada, 4(2), 113-133. http://dx.doi.org/10.1590/S1984-63982004000200007

Norris-Holt, J. (2011). Motivation as a contributing factor in second language acquisition. The Internet TESL Journal, 7(6). Retrieved from http://iteslj.org/Articles/Norris-Motivation.html

Nowak, K. L., Watt, J., \& Walther, J. B. (2006). Computer mediated teamwork and the efficiency framework: Exploring the influence of synchrony and cues on media satisfaction, and outcome success. Computers in Human Behavior, 25(5), 1108-1119. http://dx.doi.org/10.1016/j.chb.2009.05.006

Ozdener, N., \& Satar, H. M. (2008). Computer-mediated communication in foreign language education: Use of target language and learner perceptions. Turkish Online Journal of Distance Education-TOJDE, 9(2). Retrieved from http://files.eric.ed.gov/fulltext/ED501098.pdf

Rezai, A. A., \& Zafari, N. (2010). The impact of synchronous computer-mediated communication (SCMC) on the oral proficiency of Iranian EFL learners. Iranian Journal of Applied Linguistic, 13(2), 101-119.

Root, E. (1999). Motivation and learning strategies in a foreign language setting: A look at a learner of Korean. Center for Advanced Research on Language Acquisition KARLA, University of Minnesota. Retrieved from

http://www.carla.umn.edu/resources/workingpapers/documents/MotivationLearningStrategiesKoreanLe arner.pdf

Salaberry, M. R. (2000). L2 morphosyntactic development in text-based computer- mediated communication. Computer Assisted Language Learning, 13(1), 5-27.

http://dx.doi.org/10.1076/0958-8221(200002)13:1;1-K;FT005

Saleh Mahdi, H. (2014). The impact of computer-mediated communication environments on foreign language learning: A review of the literature. World Journal of English Language, 4(1), 9-19.

Samani, E., \& Noordin, N. (2013). A comparative study of the effect of recasts and prompts in synchronous computer-mediated communication (SCMC) on students' achievement in grammar. Middle-East Journal of Scientific Research, 15(1), 46-54.

Sarieva, I. (2009). Computer mediated discussions in second language writing: Intertextual connections. Paper presented at 5th International Conference in Open \& Distance Learning, Greece. Retrieved from http://artemis.eap.gr/icodl2009/ICODL_5/My\%20Webs/ICODL/A1-PDF/33.pdf

Sleesongsom, W., \& Suppasetseree, S. (2009). Chatting for improving English speaking skills in a Thai context. Foreign Language Learning and Teaching Journal, 1(2), 106-123.

Stoffa, R, Kush, J. C., \& Heo, M. (2010). Using the Motivated Strategies for Learning Questionnaire and the Strategy Inventory for Language Learning in assessing motivation and learning strategies of generation 1.5 Korean immigrant students. Education Research International, 2011. Retrieved from http://www.hindawi.com/journals/edri/2011/491276/

Sullivan, N., \& Pratt, E. (1996). A comparative study of two ESL writing environments: A computer-assisted classroom and a traditional oral classroom. System, 29(4), 491-501. http://dx.doi.org/10.1016/S0346-251X(96)00044-9

Tayebinik, M., \& Puteh, M. (2012). Txt msg n English language literacy. Procedia - Social and Behavioral 
Tahriri, A., Hassaskhah, J., \& Mozafarian Pour, A.

Sciences, 66, 97-105. http://dx.doi.org/10.1016/j.sbspro.2012.11.251

Tsai, Ch., \& Chang, I. (2013). The study of motivation and anxiety of English learning of students at a Taiwan technical university. International Journal of English Language Teaching, 1(1), 24-41.

Xiao, L. (2011). Research on motivation in foreign language learning from a new perspective. Retrieved from http://www.articlesbase.com/languages-articles/research-on-motivation-in-foreign-language-learning-fr om-a-new-perspective-5510725.html

$\mathrm{Xu}, \mathrm{Y}$. (2007). Re-examining the effects and affects of peer reviews in a first-year composition class. The Reading Matrix, 7(2), 1-21.

Yang, M., L. (2006). Exploring Taiwanese EFL students' responses to synchronous CMC: Effects on language use, learning and transfer, and perceptions. Doctoral Dissertation, University of Texas. ProQuest Information and Learning Company, UMI: 3267861.

Yilmaz, Y. (2008). Collaborative dialogue during tasks in synchronous computer-mediated communication Doctoral Dissertation, Florida State University.

\section{Appendix A}

\section{English Language Proficiency Exam (ELPE)}

In training to be a part-time car salesperson for Ford, the company has provided you with a table of information and you have been asked to write a short essay. Use the following essay question to write your essay:

Explain which vehicle would be best for a young family. Start with an introduction and thesis statement. In the body of your essay, explain why members of a young family would benefit from the car you are promoting. Finish your essay with a conclusion.

\begin{tabular}{|c|c|c|c|c|c|c|c|}
\hline Vehicle & Cost & $\begin{array}{l}\text { Number of } \\
\text { Passengers }\end{array}$ & Features & $\begin{array}{l}\text { Fuel Economy } \\
\text { Kilometers per } \\
\text { liter in the city } \\
\text { and on the } \\
\text { highway } \\
\end{array}$ & $\begin{array}{l}\text { Engine } \\
\text { size in } \\
\text { liters } \\
(\mathrm{L})\end{array}$ & $\begin{array}{l}\text { Towing } \\
\text { capacity } \\
\text { in } \\
\text { kilograms } \\
\quad(\mathrm{kg}) \\
\end{array}$ & Customer Reviews \\
\hline $\begin{array}{l}\text { Ford } \\
\text { Fiesta }\end{array}$ & $\$ 18,800$ & 5 & $\begin{array}{l}\text { 4-door } \\
\text { Front- } \\
\text { wheel } \\
\text { Drive }\end{array}$ & $\begin{array}{c}11.6 \text { city } \\
16.2 \text { highway }\end{array}$ & $1.6 \mathrm{~L}$ & $0 \mathrm{~kg}$ & $\begin{array}{l}\text { "I love this small car. It's } \\
\text { affordable and good on } \\
\text { gas. It doesn't have a ton } \\
\text { of power, but it don't } \\
\text { need power anyways." }\end{array}$ \\
\hline $\begin{array}{c}\text { Ford } \\
\text { Mustang }\end{array}$ & $\$ 26,610$ & 4 & $\begin{array}{c}2 \text {-door } \\
6 \text { speeds }\end{array}$ & $\begin{array}{c}7.7 \text { city } \\
12.5 \text { highway }\end{array}$ & $3.7 \mathrm{~L}$ & $0 \mathrm{~kg}$ & $\begin{array}{l}\text { "Great vehicle. Looks } \\
\text { great on the road, and } \\
\text { it's fun to drive. It } \\
\text { consumes a lot of gas } \\
\text { though, but I don't } \\
\text { mind." }\end{array}$ \\
\hline $\begin{array}{c}\text { Ford } \\
\text { Explorer }\end{array}$ & $\$ 41,675$ & 7 & $\begin{array}{l}\text { 4-door } \\
\text { All- } \\
\text { wheel } \\
\text { Drive }\end{array}$ & $\begin{array}{c}6.8 \text { city } \\
9.0 \text { highway }\end{array}$ & $3.5 \mathrm{~L}$ & $2267 \mathrm{~kg}$ & $\begin{array}{l}\text { "This is the toughest } \\
\text { vehicle on the road. All } \\
\text { my kids can fit, and we } \\
\text { can tow our boat easily." }\end{array}$ \\
\hline
\end{tabular}

Note. http://www.ford.com/compare/

Retrieved from: https://uwaterloo.ca/writing-centre/sites/ca.writing-centre/files/uploads/files/sample_prompt_0.pdf 


\section{Appendix B}

\section{Background Questionnaire}

1. Age:

2. Years of High School English

3. What was your average grade in English in previous courses?

4. Have you ever studied in another country? If yes, which country

5. Have you ever studied another foreign language? If yes, which language, when and for how long

6. Do you have a computer at home?

7. Do you use a computer?

8. How often do you use a computer?

9. Do you feel comfortable using a computer?

10. How would you rate your typing skills? Circle one number. 12345

11. Do you prepare your homework at computer? If yes, how often?

12. Do you use instant messaging (chat) programs, such ICQ, MSN Messenger or others? often___ (a) every day (b) several times a week (c) rarely (d) never

13. Name the programs you use 
Tahriri, A., Hassaskhah, J., \& Mozafarian Pour, A. 